\title{
REVIEW
}

\section{Enhancing Pharmacy Faculty Well-Being and Productivity while Reducing Burnout}

Daniel R. Kennedy, PhD, ${ }^{\mathrm{a}, \mathrm{b}}$ Peter Clapp, PhD, ${ }^{\mathrm{c}}$ Judith L. DeLuca, PharmD, ${ }^{\mathrm{d}}$ Theresa M. Filtz, PhD, ${ }^{\mathrm{e}}$ Lisa Kroon, PharmD, ${ }^{\mathrm{f}}$ Jennifer T. Lamberts, PhD,${ }^{\mathrm{g}}$ Catherine M. Oliphant, PharmD, ${ }^{\mathrm{h}}$ William Allen Prescott Jr., PharmD, ${ }^{\text {b,i }}$ Sidhartha D. Ray, $\mathrm{PhD}^{\mathrm{j}}$

a Western New England University, College of Pharmacy and Health Sciences, Springfield, Massachusetts
${ }^{\mathrm{b}}$ Editorial Board Member, American Journal of Pharmaceutical Education, Arlington, Virginia
${ }^{\mathrm{c}}$ Regis University, School of Pharmacy, Denver, Colorado
${ }^{\mathrm{d}}$ Wilkes University, Nesbitt School of Pharmacy, Wilkes-Barre, Pennsylvania
${ }^{\mathrm{e}}$ Oregon State University, College of Pharmacy, Corvallis, Oregon
${ }^{\mathrm{f}}$ University of California, School of Pharmacy, San Francisco, California
g Ferris State University, College of Pharmacy, Big Rapids, Michigan
${ }^{\mathrm{h}}$ Idaho State University, College of Pharmacy, Meridian, Idaho
${ }^{\mathrm{i}}$ University at Buffalo, School of Pharmacy and Pharmaceutical Sciences, Buffalo, New York
${ }^{\mathrm{j}}$ Touro College of Pharmacy, New York, New York

Corresponding Author: Daniel R. Kennedy, Western New England University, College of Pharmacy and Health Sciences, 1215 Wilbraham Road, Springfield, MA 01119. Tel: 413-796-2413. E-mail: dkennedy@wne.edu

Submitted June 9, 2021; accepted August 31, 2021; ePublished September 2021

Objective. To explore methods that pharmacy programs can use to redefine their work environment to reduce stress, improve well-being, and increase productivity.

Findings. To demonstrate a culture of support, organizations should consider a five-fold approach to enhancing and maintaining faculty well-being including, optimizing faculty and staff support, establishing a faculty development and mentoring program, permitting flexibility in work schedules, improving productivity of meetings, and managing communication tools. Individuals can also take measures to improve their well-being including controlling email, giving attention to faculty citizenship, implementing stress reduction and coping techniques, and maintaining boundaries between work and home.

Summary. This article discusses approaches that have been shown to reduce burnout and provides strategies organizations and individuals can implement to improve productivity and faculty well-being. While certain areas such as faculty wellness and productivity are well studied in the pharmacy and health professions literature, significant gaps were identified in other areas, including alternate work arrangements. In some cases, data from the business sector can be extrapolated to pharmacy education; however, inferences from effect ive corporate strategies may not be transferable to the culture and expectations of academia. While there is significant overlap between institutional and individual strategies, a culture of communication, collaboration, support and citizenship is foundational. There is no one strategy that will work for everyone and flexibility is important to develop an individualized approach.

Keywords: faculty well-being; work life balance; managing stress

\section{INTRODUCTION}

The Centers for Disease Control and Prevention (CDC) defines well-being as, "a positive outcome that is meaningful for people and for many sectors of society, because it tells us that people perceive that their lives are going well." Health benefits and lifestyle satisfaction aside, faculty who have high levels of well-being may be more productive and more engaged in their organization, the profession, and their community. Striving to optimize the well-being of pharmacy faculty is vital to promote success among individual faculty, schools/colleges of pharmacy, and the Academy as a whole. Burnout, which is the culmination of emotional exhaustion, depersonalization, and decreased personal accomplishment, threatens this ideal. ${ }^{2,3}$ As a call to action for pharmacy education, Darbishire and colleagues published a commentary in 2020, in which they stated, "the Academy must proactively evaluate, develop, and implement strategies to minimize faculty burnout." 4

As is the case in other health professional schools, pharmacy faculty are prone to burnout. ${ }^{2,3}$ In a 2012 survey of 811 US pharmacy faculty members, $64 \%$ reported that they were very/extremely satisfied with their current position in 
academia. ${ }^{3}$ However, only $37 \%$ of respondents indicated being very/extremely satisfied with their work-life balance, suggesting that while pharmacy faculty enjoy their careers, it impedes their ability to achieve the balance they desire. ${ }^{3} \mathrm{~A}$ second survey conducted in 2014 assessed the prevalence of burnout and sought to identify associated factors among pharmacy practice faculty. In this study, $41 \%$ and $11 \%$ of respondents reported high levels of emotional exhaustion and depersonalization, respectively, while $24 \%$ reported low levels of personal accomplishment. ${ }^{2}$ Emotional exhaustion and depersonalization were higher, and perceptions of personal accomplishment lower, among faculty with young children and those who indicated not having a hobby, while emotional exhaustion and depersonalization were especially prevalent among faculty without a mentor. ${ }^{2}$ Gender also appears to play a role in faculty burnout, as female faculty members who responded to the survey reported higher rates of emotional exhaustion and lower rates of personal accomplishment. ${ }^{2}$

Despite the plethora of evidence demonstrating the pervasiveness of burnout among pharmacy faculty and the detrimental effects burnout has on individual and institutional well-being, evidence-based interventions that address how to mitigate burnout in pharmacy academia are lacking. ${ }^{5}$ Just as an academician relies on the literature to guide best practices in teaching and research, administrators and individuals in positions of leadership should rely on quality of work/life studies to guide organizational decisions and policy development. The 2020-2021 Department Chair Community of the American Association of Colleges of Pharmacy (AACP) Council of Faculties was charged with exploring strategies for enhancing well-being and minimizing burnout among pharmacy faculty.

This review provides an overview of strategies that can be adopted to encourage faculty well-being and productivity, while mitigating the risk of burnout. This review was informed by a literature review, conversations among members of the Department Chair Committee of the AACP Council of Faculties, and discussions with stakeholders during the 2021 AACP Interim Meeting.

\section{Institutional Approaches to Support Well-being}

The influence an organizational culture can have on faculty well-being cannot be understated. For instance, a competitive environment, when taken to the extreme, can negatively influence stress levels within and across units. In contrast, a culture of collaboration improves morale and propagates positivity among colleagues. Furthermore, a culture of modeling and leading by example can promote teamwork and effective group dynamics.

Institutional approaches should begin with a thorough evaluation of factors associated with faculty burnout and a commitment to identifying and meeting faculty needs. ${ }^{4}$ When faculty perceive that they are supported by their institution, feelings of burnout are mitigated. There are several effective ways to demonstrate a culture of institutional support including providing resources for professional development in teaching, scholarship, and service; acknowledging appreciation for faculty effort; aligning faculty and institutional goals; providing guidance, feedback, supportive mentoring and encouragement; and reassuring faculty of their value. ${ }^{5}$ An institutional culture of support develops when these behaviors are modeled by administrators and permeate through faculty interactions with each other. Other behaviors from administrators that demonstrate a culture of institutional support include promoting transparency in expectations of faculty and staff, developing clear criteria for tenure and promotion, following through on commitments, providing adequate staff support, creating orientation programs for new faculty, engaging faculty in the decision-making process, encouraging social interaction and relationship building, providing wellness and stress reduction programs, and rewarding faculty achievements in a manner that is equitable. ${ }^{5}$

Department chairs have significant responsibility when it comes to promoting a healthy organizational culture at their institutions. ${ }^{5}$ First and foremost, one of the most important things a chair can do is develop effective individual coping mechanisms to prevent the likelihood of burnout in themselves. As is often said, chairs have one of the most difficult jobs at a university, serving as a bridge between the faculty and the administration. Given the high expectations of the position, chairs must first "put on their own oxygen masks" before they can assist others, because the ramifications of a burned-out chair can be significant. After individual resilience, chairs can use several other strategies to help prevent burnout in their faculty. These behaviors include, but are not limited to, effective communication, empowering others, promoting collegiality, and establishing a judgement-free culture.

To demonstrate a culture of support, organizations should consider a five-fold approach to enhancing and maintaining faculty well-being including: (1) optimizing faculty and staff support (2) establishing a faculty development and mentoring program, if one is not already in place; (3) permitting flexibility in work schedules; (4) improving productivity of meetings; and, (5) managing communication tools.

Institutions can adopt many strategies to optimize faculty and staff support, including reevaluating workflow and responsibilities, optimizing roles of support staff to improve efficiency, considering alternative work models such as job sharing, and investing in wellness programs. In addition, institutions can provide support for child or elder care, such as 
establishing a care center on campus, connecting with a local care center, and/or providing financial support to employees (eg, negotiating reduced rates or offering flexible spending programs).

During annual faculty performance reviews, department chairs and faculty can work together to identify current challenges and then develop strategies for improvement. For example, if a faculty member struggles to manage their teaching workload, the chair/faculty member should consider alternatives to managing workflow (e.g, working smarter, not harder), reallocating teaching responsibilities, and/or identifying activities that can be allocated to support staff. Where possible, creating technological solutions may improve efficiency (eg simplifying or consolidating software platforms and use of learning management software to assist faculty and staff).

For faculty with clinical practice responsibilities, similar considerations apply. For example, chairs should meet with leaders at practice sites to set/realign patient care expectations so that faculty are able to satisfy their other academic responsibilities (eg, didactic teaching, service, scholarship) that may not be apparent to colleagues at clinical practice sites. To ensure continuity of patient care, multiple faculty can share patient care responsibilities (eg., having a rotating schedule for coverage) and/or collaborate with practice site staff. These strategies not only have the potential to improve faculty contributions to practice-site goals, but can also improve faculty workload balance.

Job sharing, where two people work on a part-time or reduced-time basis to perform a job normally fulfilled by one full-time person, can be beneficial for some faculty. In addition to the flexibility, Sacks and colleagues cite other advantages to job sharing such as peer mentorship and collective brainstorming on ideas and problems. ${ }^{6}$ It also can be beneficial for clinical faculty to provide more continuity in covering patient care activities. To realize the full benefits of job sharing, it is important to remember that it is the sharing of one position, not two independent part-time jobs. ${ }^{6}$

Lastly, an investment in wellness programs for faculty and staff demonstrates a culture of institutional support. If an institution is not able to develop their own, outsourcing to existing programs should be done, and made available either free or at very low-cost. Faculty and staff should be given protected time to participate in wellness programs.

In addition to optimizing support with the strategies discussed above, faculty development and mentoring are key aspects to a culture of institutional support. This begins with an organized approach to onboarding new faculty and continues through collaborative mentoring, a longitudinal approach to faculty development, setting of clear expectations, and providing ongoing review of performance and progress towards goals. ${ }^{7}$ Faculty development and mentoring can be a key to attracting and retaining talented pharmacy faculty., 8

While faculty development begins with new faculty, it doesn't end there. Faculty development in the areas of new technology, teaching, scholarship, service, and work-life balance are needed throughout the beginning, mid, and advanced stages of a career in academia. Furthermore, faculty can be empowered to teach each other about their areas of skill and interest, having the added benefit of strengthening relationships while creating a longitudinal approach to faculty development. Including the organization as a partner in collaboration with a mentor and mentee can support morale within an organization while also mitigating faculty burnout. ${ }^{8}$ This model can also reduce workplace stress, lessen the risk of attrition, improve recruitment, and expand the pool of mentors within an organization long-term (ie, when a mentee transitions into the role of mentor). Consequently, mentoring not only strengthens individual faculty members, but the organization as a whole. In 2008, Fuller and colleagues published a call to action, stating, "Colleges of pharmacy that determine they do not have an effective mentoring program should strongly consider implementing the triad model of mentoring," where the organization is added to the typical dyad model of a mentor and protégé. ${ }^{8}$ Although this call is more than a decade old, it continues to resonate within the Academy.

Beyond faculty development and mentoring, institutional support for openness to flexible options to balance work and life demands can mitigate faculty stress and improve job satisfaction. When institutions and supervisors provide flexibility in scheduling responsibilities for faculty, the faculty can be empowered to arrange their time in the manner in which they can be most productive, while still meeting organizational expectations and needs. A recent Gallup poll found that $51 \%$ of respondents prefer a job that offers flextime. ${ }^{9}$ Greater flexibility can improve autonomy to manage one's own workload. ${ }^{10}$ This in itself can improve efficiency and productivity and increase happiness, personal worth, and morale. Options for greater flexibility that organizations can consider include a compressed work week, telecommuting one or more days per week, and a flexible schedule that would allow the faculty member to come and go during the day. The Harvard Business Review encourages employers to allow employees to have a bigger role in determining the work schedules that are best for them, while still meeting the needs of the institution. ${ }^{9}$ Yet, it is important that these options for flexible schedules be applied equitably across faculty positions.

Furthermore, flexibility is increasingly important to workers and can impact recruitment and retention. Millennial and Generation $\mathrm{Z}$ workers list work schedule flexibility as a major influence in considering potential employers. ${ }^{11}$ The Flex Jobs 2019 Annual Survey found that $30 \%$ of workers reported leaving a position because of non-flexible work options. ${ }^{12}$ One potential mechanism to create work flexibility is to adopt a four-day work week, as one 2020 Harris Poll 
found that $82 \%$ of US employees surveyed said they preferred a reduced work week, even if they had to work longer days. ${ }^{13}$ Several countries, including the United Kingdom, Spain, Finland, New Zealand, and Japan, have embraced the four-day work week in the corporate world with positive results. ${ }^{14}$ One example includes Perpetual Guardian, a company in New Zealand, who implemented a four-day work week and realized improved productivity and employee satisfaction. ${ }^{14}$ Another example is Microsoft Japan, who gave employees Fridays off and netted a $40 \%$ increase in productivity. ${ }^{15}$ Employers who are using the four-day work week report enhanced well-being, improved mental and physical health, and reduced absenteeism.

There are advantages and disadvantages of a four-day work week. Reported advantages include 1) increased employee productivity/efficiency, satisfaction, morale, retention, happiness, and personal worth; 2) stronger families and communities; 3) cost savings related to transportation and dependent care costs; and 4) reduced absenteeism, anxiety, stress, and burnout. ${ }^{10}$ The primary disadvantage of a four-day work week is fatigue due to longer work days, if a 40 hour work week is maintained. This may actually increase stress and reduce productivity in some cases. Moreover, not all faculty models are amenable to a four-day work week. For instance, while a program could schedule didactic teaching within 4-days, it is unlikely that faculty with clinical and experiential education responsibilities or those who are partially compensated by the practice site, could easily adopt this model. Similarly, faculty in leadership roles would be challenged to have a four-day week, as issues may occur at work on the off days that require their attention.

Another factor in creating a culture of institutional support is ensuring meetings are meaningful and productive.

Meetings in academic departments are ubiquitous and often maligned as a huge waste of time. While meetings have a functional role in supporting the operational goals of an academic unit, they also serve as a platform for institutional discourse and are a reflection of institutional culture. ${ }^{16}$ Meetings that are well-designed and purposeful can strengthen connections between participating faculty and the values of the institution. On the other hand, meetings that are inefficient or unnecessary may be a detriment to faculty well-being and productivity.

In his often-cited book Death by Meeting, Patrick Lencioni highlights many possible pitfalls that face the organizers of institutional meetings. ${ }^{17}$ One is the creation of "meeting stew", or the tendency to pack too many unrelated topics into the same agenda. productivity. A few simple rules for organizing an academic meeting can help to minimize negative perceptions. An agenda that includes a purpose, outcome, and plan for each item should be sent to all attendees ahead of the meeting. ${ }^{18}$ Meeting attendees should be engaged in a time-limited discussion on each topic, with a goal of achieving closure before the meeting is scheduled to end. ${ }^{19}$ Institutions and their leaders should be cognizant of the need, length, frequency, and focus of meetings while balancing the number of people who truly need to attend to accomplish its goals. Obviously, some meetings are necessary, while other issues can be handled by email or by executive decision. Lastly, restricting meeting days or times can be a useful strategy in helping faculty with time management.

Similar to meetings, email is a communication tool that can have positive and negative impact on faculty wellbeing. If not managed effectively, email can contribute to a sense of overload ${ }^{20}$ and a blurring of boundaries between work and home, which adds to stress and increases burnout. ${ }^{21}$ Email can also increase workload and disrupt concentration, reducing productivity. ${ }^{22}$ Furthermore, to be useful sources of information for later use, emails require a manageable and logical system of sorting and filing.

While various strategies for managing email are reported (eg, sorting, prioritizing, archiving) ${ }^{23}$ many appear to have very little effect on stress associated with email volume. ${ }^{20}$ Other strategies that are applicable to improving wellness, such as setting email expectations modeled by leadership and promoting the use of alternative communication tools, show promise. ${ }^{24}$ Setting boundaries around work and home time by maintaining good "email hygiene" is one strategy that has been emphasized. Late-night emails from leadership can infectiously transpire a specific pattern within a team or an organization; this can undoubtedly send a bad prototype of work habit. ${ }^{25}$ Effective leaders should emphasize and model the importance of scheduling both focused work time without electronic interruptions, and consistent downtime. ${ }^{25}$ This applies even more when working remotely, where the definitions of work and home are blurred. Organizations can promote better email hygiene and improve wellness by discussing expectations for monitoring and responding to email and promoting common downtimes. ${ }^{24}$ In one example, email-free hours were instituted from 10 PM to 7 AM weekdays and all weekend days when everyone, including leadership, agreed to refrain from communication except in a true emergency. ${ }^{25}$ An automated solution for those who work best at odd hours may be to use a program that will delay sending emails until normal work hours and thus unburden others of the expectations to check and respond outside of regular business hours.

Additional strategies to improve email management focus on efficiency and clarity. By eliminating needless emails such as "Thanks" and "Got it", email volume can be reduced. Implementation of such an approach should be preceded by a company or unit-wide conversation around email acknowledgements to change the culture and avoid the perception of lost emails or a lack of gratitude. Other ideas include creating template emails for common responses or 
using communication tools other than email (eg, instant messaging apps, telephone or video conferencing). Different tools have benefits for different forms of communication, such as collaborations that require dialogue or depend upon the use of shared documents. A unit-wide discussion about the most appropriate use of each tool is likely to produce better results.

\section{Individual Approaches}

While institutional culture and expected norms can be sources of stress and overload, individuals can also adopt strategies to increase their own productivity, improve job satisfaction, reduce stress and mitigate the persistent creep of work into their home lives. These include: (1) controlling email; (2) giving attention to faculty citizenship; (3) implementing stress reduction and coping techniques; and (4) maintaining boundaries between work and home.

While it would require an institutional shift to make widespread changes in email practices, individuals can apply several strategies to improve well-being. Faculty can mitigate interruptions and the time they spend on email by turning off email alerts and scheduling times to work on email during the day. Studies suggest that checking email fewer times per day reduces stress and improves several measures of well-being. ${ }^{26}$ Processing email in batches at scheduled times and self-planned interruptions for email led to greater feelings of daily productivity and less stress as compared to workers who used auto reminders for email notifications. ${ }^{27}$ Strategies for managing others' expectations for email responses include putting a notification in your signature line that advises when you regularly check email. ${ }^{28}$ The subject line can also be used more effectively, using terms such as "action required", "sign", "info", "decision" "request" "coordinate" to detail the response you desire from the recipient.

A recent AACP Council of Faculties Faculty Affairs Committee was charged with defining faculty citizenship as it relates to pharmacy education. The committee's published definition was "a pattern of behaviors by pharmacy faculty members that promotes the welfare of the school or college of pharmacy, and as a consequence, the larger university structure." ${ }^{29}$ The key distinction between service and citizenship is that citizenship goes beyond the required and defined set of service activities as part of one's contract and it is seemingly an informal criteria that exists within the culture of a program. ${ }^{29}$

Positive faculty citizenship behaviors have been suggested to include intentional civility in interactions with faculty, staff and students; verbal and nonverbal signs of respect; and self-motivated collaboration and cooperation on departmental, teaching, and scholarly activities. ${ }^{30}$ These patterns of behavior promote the institution and profession and contribute to a positive and productive work environment. ${ }^{29}$ Faculty should take care to be aware of how their manifestations of stress may potentially cause negative interactions with others, decreasing productivity and harming a workplace culture. Similarly, rewards and recognition of positive faculty citizenship can also lead to more enhanced organizational culture.

Stress is complex and it is often difficult to establish a cause-effect relationship between stress generators and burnout. Regardless, stress in any form can impact productivity and success. ${ }^{31}$ The vast majority of literature on the subject of reducing personal stress suggests benefits to lifestyle modifications, physical activity, mindfulness meditation, relationship building, social networking, consulting a mentor, delegating assignments, reducing tasks, and using smart time management strategies. As a first step, identifying the cause(s) of stress is critical for the identification of effective strategies. Second, an individual's motivation and willingness to try these suggested strategies is central to lessening stress. Third, recognizing that there is no shame in reaching out to others for help. Likewise, department chairs, supervisors, and experienced mentors should remain proactive in reaching out to individuals who are showing signs of stress or openly disclose their need for assistance. Colleagues who show palpable signs of stress must be provided with necessary support and help, which may require professional help or counseling beyond what the workplace is able to provide. Open communication is of paramount importance to determine the root cause(s) of stress in order to provide personalized support and advice. ${ }^{32,33}$

By prioritizing realistic personal and professional goals while keeping work-life balance in focus, faculty can create healthy boundaries between work and home. This may include advocating for oneself to supervisors if workload expectations are unrealistic and becoming comfortable with declining to take on additional responsibilities. It may also include finding others within and outside of your organization to collaborate with on projects in an effort to better distribute workload.

\section{CONCLUSION}

This article discusses approaches that have been shown to reduce burnout and provides strategies organizations and individuals can implement to improve productivity and faculty well-being. While certain areas such as faculty wellness and productivity are well studied in the pharmacy and health professions literature, significant gaps were identified in other areas, including alternate work arrangements. In some cases, data from the business sector can be 
extrapolated to pharmacy education; however, inferences from effective corporate strategies may not be transferable to the culture and expectations of academia. While there is significant overlap between institutional and individual strategies, a culture of communication, collaboration, support and citizenship is foundational. There is no one strategy that will work for everyone and flexibility is important to develop an individualized approach. A key element in this process is that both the institutional leadership and individual faculty must be motivated and willing to make well-being a priority, helping to improve faculty productivity, job satisfaction and work life balance.

\section{ACKNOWLEDGMENT}

The authors are grateful to Michelle Assa-Eley for the wonderful support she provided us as the AACP staff liaison during this project.

\section{REFERENCES}

1. Well-Being Concepts. Center for Disease Control and Prevention. Available at: https://www.cdc.gov/hrqol/wellbeing.htm. Accessed June 8th 2021.

2. El-Ibiary SY, Yam L, Lee KC. Assessment of Burnout and Associated Risk Factors Among Pharmacy Practice Faculty in the United States. American Journal of Pharmaceutical Education. 2017;81(4):75.

3. Lindfelt TA, Ip EJ, Barnett MJ. Survey of career satisfaction, lifestyle, and stress levels among pharmacy school faculty. American journal of health-system pharmacy : AJHP : official journal of the American Society of HealthSystem Pharmacists. Sep 15 2015;72(18):1573-8.

4. Darbishire P, Isaacs AN, Miller ML. Faculty Burnout in Pharmacy Education. American Journal of Pharmaceutical Education. 2020;84(7):ajpe7925.

5. Desselle S, Darbishire P, Clubbs B. Pharmacy Faculty Burnout: Cause for Concern that Requires Our Support and Use of Best Evidence. INNOVATIONS in pharmacy. 2020;11(3):12.

6. Sacks J, Valin S, Casson RI, Wilson CR. Are 2 heads better than 1? Perspectives on job sharing in academic family medicine. Canadian family physician Medecin de famille canadien. Jan 2015;61(1):11-3, e1-3.

7. Prescott WA. Facilitating Advancement of Clinical-Track Pharmacy Faculty Members. American Journal of Pharmaceutical Education. 2020;84(5):7910.

8. Fuller K, Maniscalco-Feichtl M, Droege M. The role of the mentor in retaining junior pharmacy faculty members. Am J Pharm Educ. Apr 15 2008;72(2):41.

9. Bolino M, Kelemen T, Matthews S. Rethinking Work Schedules? Consider These 4 Questions. Harvard Business Review. Available at: https://hbr.org/2020/07/rethinking-work-schedules-consider-these-4-questions. Accessed May 26th 2021.

10. Fontinha R, Walker J. Four Better or Four Worse. Henley Business School. Available at: https://assets.henley.ac.uk/v3/fileUploads/Journalists-Regatta-2019-White-PaperFINAL.pdf?mtime=20200923092629\&focal=none. Accessed May 26th 2021.

11. Laker BR, T. Will the 4-Day Workweek Take Hold in Europe? Harvard Business Review. Available at: https://hbr.org/2019/08/will-the-4-day-workweek-take-hold-in-europe. Accessed May 26th 2021.

12. Agovino T. Society of Human Resource Management. Available at: https://www.shrm.org/hr-today/news/allthings-work/pages/four-day-workweek.aspx. Accessed May 26th 2021.

13. Manskar N. Support for four-day workweek soars amid coronavirus crisis Available at: https://nypost.com/2020/06/05/support-for-four-day-workweek-soars-amid-coronavirus-crisis/. Accessed May 26th 2021.

14. Berger M. Will the coronavirus pandemic open the door to a four-day workweek? Available at: https://www.washingtonpost.com/world/2020/05/24/will-coronavirus-pandemic-open-door-four-day-workweek/. Accessed May 26th 2021.

15. Toh M, Wakatsuki Y. Microsoft tried a 4-day workweek in Japan. Productivity jumped 40\%. CNN. Available at: https://www.cnn.com/2019/11/04/tech/microsoft-japan-workweek-productivity/index.html. Accessed May 26th 2021.

16. Volle M. Exploring the relationship of meetings to organizational culture and values. Pepperdine Theses and Dissertations 2016.

17. Lencioni P. Death by Meeting. Hoboken, NJ: Jossey-Bass; 2004.

18. Kjellberg BJ, Saxton EL. How to Avoid Death by Meeting. The Serials Librarian. 2006/05/10 2006;50(1-2):21-6. 
19. Berk RA. Meetings in academe: It's time for an "EXTREME MEETING MAKEOVER! The Journal of Faculty Development. 2012;26(1):50-3.

20. Jerejian ACM, Reid C, Rees CS. The contribution of email volume, email management strategies and propensity to worry in predicting email stress among academics. Comput Hum Behav. / 2013;29(3):991-6.

21. Boswell WR, Olson-Buchanan JB. The Use of Communication Technologies After Hours: The Role of Work Attitudes and Work-Life Conflict. Journal of Management. 2007/08/01 2007;33(4):592-610.

22. Bellotti V, Ducheneaut N, Howard M, Smith I, Grinter RE. Quality Versus Quantity: E-Mail-Centric Task Management and Its Relation With Overload. Human-Computer Interaction. 2005/06/01 2005;20(1-2):89-138.

23. Barley SR, Meyerson DE, Grodal S. E-mail as a Source and Symbol of Stress. Organization Science. 2011;22(4):887-906.

24. Becker WJ, Belkin LY, Conroy SA, Tuskey S. Killing Me Softly: Organizational E-mail Monitoring Expectations' Impact on Employee and Significant Other Well-Being. Journal of Management. 2021/04/01 2019;47(4):1024-52.

25. Thomas M. Your Late-Night Emails Are Hurting Your Team Harvard Business Review. Available at: https://hbr.org/2015/03/your-late-night-emails-are-hurting-your-team. Accessed May 26th 2021.

26. Kushlev K, Dunn EW. Checking email less frequently reduces stress. Computers in Human Behavior. 2015/02/01/ 2015;43:220-8.

27. Mark G, Iqbal ST, Czerwinski M, Johns P, Sano A, Lutchyn Y. Email Duration, Batching and Self-interruption: Patterns of Email Use on Productivity and Stress. Proceedings of the 2016 CHI Conference on Human Factors in Computing Systems. San Jose, California, USA: Association for Computing Machinery; 2016:1717-28.

28. Peck S. 6 Ways to Set Boundaries Around Email Harvard Business School. Available at: https://hbr.org/2019/09/6-ways-to-set-boundaries-around-email. Accessed May 26th 2021.

29. Hammer DP, Bynum LA, Carter J, et al. Revisiting Faculty Citizenship. American Journal of Pharmaceutical Education. 2019;83(4):7378.

30. Easterling W. Collegiality: A singular concept? IndianaUniversity-Purdue University Indianapolis (IUPUI) ScholarWorksRepository. 2011.

31. Bhui K, Dinos S, Galant-Miecznikowska M, de Jongh B, Stansfeld S. Perceptions of work stress causes and effective interventions in employees working in public, private and non-governmental organisations: a qualitative study. BJPsych Bull. 2016;40(6):318-25.

32. Tams S, Ahuja M, Thatcher J, Grover V. Worker stress in the age of mobile technology: The combined effects of perceived interruption overload and worker control. The Journal of Strategic Information Systems. 2020/03/01/ 2020;29(1):101595.

33. Tetrick LE, Winslow CJ. Workplace Stress Management Interventions and Health Promotion. Annual Review of Organizational Psychology and Organizational Behavior. 2015;2(1):583-603. 